\title{
Predictors of Women's Emergency Contraception Use and Men's Support of Partner's Use among College Students
}

\author{
Veronica Fitzpatrick, Michele Mouttapa, Sora Park Tanjasiri, and James Napoli \\ Department of Health Science, California State University, Fullerton
}

\begin{abstract}
Background: The unintended pregnancy rate in the United States is high, and emergency contraception (EC) is a birth control method that prevents unintended pregnancies. Despite the fact that many college campuses provide access to EC, undergraduate college students have relatively high rates of unintended pregnancies. Purpose: This study examined whether perceptions and knowledge regarding EC use were associated with women's intentions to use EC, and men's intentions to support their partner's EC use. Methods: This study utilized a convenience sample of 96 female and 118 male southern California community college undergraduate students. Results: Women had stronger intentions to use EC if they thought they could successfully obtain it at a pharmacy, while men reported they were more likely to support a partner's use if they thought that EC use is morally acceptable. Conclusions: The findings suggest that increasing women's knowledge about the accessibility of EC may lead to increased use of EC if needed. Men's moral stance regarding EC use may impact the degree to which they will support their female partners using EC. Further implications are discussed.
\end{abstract}

(c) 2014 Californian Journal of Health Promotion. All rights reserved.

Keywords: Emergency Contraception, knowledge, intentions, beliefs, men

\section{Introduction}

According to the Centers for Disease Control and Prevention (CDC, 2014), unintended pregnancies are those that were mistimed (wanted later) and/or unwanted. From 2001 to 2008, the percentage of total pregnancies that were unintended in the United States increased from $48 \%$ to $51 \%$, which translates to additional tens of thousands of pregnancies in a given year (Finer \& Zolna, 2014). In 2006, women who were of college age (e.g., 18 to 24 years old) had higher rates of pregnancies that were unintended (between 63\% and 84\%; Finer \& Zolna, 2011). Although higher education has been associated with higher rates of contraceptive use $(\mathrm{Wu}$, Meldrum, Dozier, Stanwood, \& Fiscella, 2008), an estimated $1.7 \%$ of female college students reported experiencing an unintended pregnancy within the past 12 months in 2013 (American College Health Association-National College Health Assessment II, 2013). This suggests that continued efforts to prevent unintended pregnancies among college students are highly needed.

The direct medical costs of unintended pregnancies were \$5 billion in 2002 (Trussell, 2007). Children resulting from unintended pregnancies have lower scores of overall wellbeing and poorer developmental outcomes (Hummer, Hack \& Raley, 2004; de La Rochebrochard \& Joshi, 2013). Problems accessing contraception and discontinuation of contraception have been commonly reported reasons for unintended pregnancies among women attending family planning and prenatal clinics (Iuliano, Speizer, Santelli \& Kendall, 2006). In one study, underestimating the risk of pregnancy was the most frequently-reported reason for not using contraception among women seeking an abortion. Only 38\% of the women reported knowing that they were at risk of getting pregnant when they had intercourse that later ended in pregnancy (Moreau, Bouver, Goulard \& Bajos, 2005). 
In response to the high prevalence of unintended pregnancies and its adverse health consequences, Healthy People 2020 includes objectives to improve pregnancy planning, spacing, and preventing unintended pregnancy. One objective is to increase the proportion of pregnancies that are intended from approximately $50 \%$ in most recent assessments to $56 \%$ in 2020 (U.S. Department of Health and Human Services, 2014). Family planning efforts that can help reduce unintended pregnancy include increasing access to contraception and increasing correct and consistent use of contraceptive methods among those who are sexually active but wish to delay or avoid pregnancy (CDC, 2014).

\section{Emergency Contraception}

Emergency contraception (EC) is a form of contraception that can prevent pregnancy after unprotected sexual intercourse has occurred (Trussel, Ellertson \& Stewart, 1996). The Food and Drug Administration (FDA) first approved EC prescription pills in 1998, but there is documented evidence of some use of hormonal contraceptives for EC as early as the 1960s (Ellertson, 1996). To maximize EC's effectiveness of preventing conception, oral EC needs to be taken within 12 hours following unprotected intercourse; but EC can be $75 \%$ effective for up to 72 hours (CDC, 2010).

EC has become increasingly accessible in recent years. In June 2009, the FDA approved "Plan B" to be available to women over the age of 17 without a prescription. In 2013, Plan B became available to females of all ages without a prescription (FDA, 2013). In 2011, approximately $62 \%$ of California community college student health centers provided EC to students (Trieu, Shenoy, Bratton \& Marshak, 2011).

EC use is higher among college-aged women. Between 2006-2010, about one in nine (11\%) sexually experienced U.S. women ages 15-44 years reported using EC at least once, compared to $23 \%$ of women between $20-24$ years. EC use is also more common among those who never married, Hispanic or White women, and those who have attended college (Daniels, Jones \&
Abma, 2013). In another study, approximately $28 \%$ of sexually active female university students had used EC (Hickey, 2009).

Despite the higher rates of EC use among college aged women, even higher rates of EC use are needed, evidenced by the increased percentage of unintended pregnancies from 2001 to 2008 (Finer \& Zolna, 2014). Possible ways to increase EC use is to increase knowledge about EC facts and consider attitudes both women and men have regarding EC use.

Emergency Contraception Knowledge. A lack of knowledge about EC and its availability may lead to lower rates of use. In California, EC awareness has increased among women from 40\% to 57\% between 1999 and 2004 (Foster, Ralph, Arons, Brindis \& Harper, 2006). Despite these encouraging findings, there is room for improvement. In one study, only half of the women surveyed were able to correctly identify 72 hours as the effective time period to take EC following unprotected sex (Whitaker, Berger, Armstrong, Felice \& Adams, 2007). Another study indicated that several women were not able to distinguish RU-486 (the "abortion pill”) from EC, which prevents conception in the first place (Hickey, 2009). Other gaps in knowledge documented among women that may inhibit their EC use include misperceptions about the effectiveness of EC, common EC side effects (including infertility), and that it is approved by the U.S. government (Miller, 2011; Shoveller, Chabot, Soon \& Levine, 2007). In another study, the majority (60\%) of students who had access to EC on their own college campus did not know that they could obtain it there (Hickey, 2009).

Attitudes toward Emergency Contraception. More favorable attitudes toward EC use may lead to a greater likelihood of using EC when needed. In one study, negative feelings toward pregnancy were the strongest predictors of recent EC use among women attending publicly funded family planning clinics (Whitaker et al., 2007). In another study among undergraduate college students, males were more receptive toward females using EC if they [males] were more knowledgeable about EC facts (Miller, 2011). Research has also shown that about $86 \%$ 
of college aged students approved of EC in the event of contraception failure, and $68 \%$ approved of it in the event of unprotected sexual intercourse (Vahratian, Patel, Wolff, and $\mathrm{Xu}$, 2008).

\section{Men's Support Role in Contraceptive Use}

Historically women are studied more frequently about EC than men, because women are the direct consumers of most contraceptives. It is important, however, to consider men's role in their female partners' contraceptive decisions. Previous research suggests that males have the potential to provide support (e.g., knowledge, advice, emotional support) and to assist their female partners in women's health issues. For example in one initiative, California's Male Involvement Program (MIP), there is a statewide effort to involve young adult males in teen pregnancy prevention efforts (Brindis, Barenbaum, Sanchez-Flores, McCarter \& Chand, 2005). Another study of Pacific Islander adults suggested that a cervical cancer screening program which involves husbands/male partners can have a stronger impact on cervical cancer screening rates, beyond the impact of traditional cancer prevention strategies that aim only to increase women's knowledge about their own cancer risk (Tanjasiri, Mouttapa, Sablan-Santos, \& Quitugua, 2012). In regards to EC, another study found that only $67.6 \%$ of men thought that EC could in fact prevent a pregnancy (Nguyen \& Zaller, 2009). It is possible that by increasing men's knowledge about EC facts, they may be better able to provide social support for their female partners to use EC, if needed.

\section{The Present Study}

This study examined whether perceptions and knowledge regarding EC are associated with intentions to use EC among undergraduate student women, and men's intentions to support their partner's use of EC. It is important to examine EC use among female college students because the majority of them represent an age group (18-24 years) that is at highest risk for unintended pregnancies (Finer \& Zolna, 2011). Furthermore, research is needed to determine whether college men are a feasible target population for pregnancy prevention efforts, as
Brindis and colleagues (2005) have found it to be the case among teenage males.

\section{Methods}

\section{Study Design and Participants}

This study utilized a quantitative, design with a convenience sample of southern California community college students who were enrolled in one of six personal health classes during the fall 2009 and spring 2010 semesters. Self-report surveys were administered to all eligible students (age 18 years and older) before any contraception information had been covered in the course curriculum. There were no sexual behavior-related exclusion criteria, since the main outcomes were intention-based and not behavior-based. For this reason, sexuality, current relationship status, and current sexual behavior were not used as predictive variables to measure intentions to use EC (for women), and supporting one's partner to use EC (for men). Out of the 216 individuals approached to participate in the study, 214 completed surveys for an overall response rate of $99 \%$ (100\% for females and $98.3 \%$ for males).

\section{Procedures}

All procedures and instruments utilized in this study received IRB approval from the authors' institution prior to implementation. Permission to administer surveys was obtained from the Physical Education and Athletics department at the junior college where the data were collected. Permission was also obtained from the course instructor to visit each of her personal health classes and administer surveys to her students during class time. Surveys were six pages in length with approximately 50 questions.

The surveys were distributed and collected by the first author. All potential participants were briefed about the contents of the survey and given the opportunity to leave the classroom if they did not want to participate. All participants provided written informed consent, and were asked to fill out the survey on their own. The investigator stayed the entire time to answer any questions the participants may have had about the survey. Once a participant completed the survey, the investigator immediately collected 
the survey and the participant left the classroom. No incentive was given for participation.

\section{Measures}

The independent variables were knowledge of EC, perceptions about EC, and past experiences with pregnancy, while the dependent variables were intentions to use EC (for women) and intentions to support partner's use of EC (for men).

Knowledge of EC. Knowledge of EC items were adopted from Vahratian, Patel, Wolff, and $\mathrm{Xu}$ (2008) and Hickey (2009). They consisted of six multiple choice questions including: "How long after unprotected vaginal intercourse does emergency contraception remain effective" (with five possible response options ranging from "1day" to "5 days"); and "What is the difference between emergency contraception (plan B) and RU-486 (mifepristone) the 'abortion pill?" Response options to the second question were: "There is no difference", "EC is taken only before a pregnancy has occurred and RU-486 is taken after pregnancy has occurred", "They can both terminate an already existing pregnancy", and "Neither RU-486 nor EC require a prescription, they are both over the counter." In addition, the following questions were asked: "Can you get emergency contraception pills or the 'morning after pill' over the counter from your drug store pharmacist without phoning or seeing the doctor first?"; "Can you obtain EC over the age of 17 in the state of California?”; "Can you obtain EC in any pharmacy in California?"; and "Is another person legally allowed to purchase EC for you, if needed?" Possible answers to these questions were "yes" and "no."

Perceptions about EC. These items were adapted from the Affective Responses toward Contraception Topics and Behavior Scale (Kelley, 1998). We adapted six of the items to specifically assess EC use perceptions. They were the following: "I feel emergency contraception use is morally wrong”, "Using emergency contraception is much more desirable than having an abortion", "Emergency contraception encourages promiscuity", "Emergency contraception is worth using, even if the monetary cost is high”, “Teenagers should not need permission from their parents to obtain emergency contraception", and "Females who use emergency contraception are promiscuous." All of these items had the response options of "strongly agree”, "agree”, "undecided", “disagree”, and "strongly disagree.” Cronbach's alpha was .61 for these items.

\section{Past Experiences with Sexual Intercourse, Pregnancy and Contraception Use.} Participants were asked the following: "Have you ever had vaginal intercourse (penis inserted into a vagina)", "have you (or a partner) ever been pregnant" and "have you (or a partner) ever used emergency contraception", and "have you (or a partner) ever had or experienced an abortion", with the response options of "yes" and "no" for all of these items. Survey items were adapted from the National Longitudinal Study of Adolescent Health, Waves 1 and 2 (Udry, 2003).

Intention to Use EC/Support Partner to Use EC. Intention to use EC was the nt variable for females in this study, while intention to support one's partner to use EC was the dependent variable for males. The question that was asked of females was, "Would you ever use emergency contraception or the 'morning after pill' if your first method of birth control failed?" The question that was asked of males was, "Would you encourage your partner to use emergency contraception or the 'morning after pill' if your first method of birth control failed?" Both questions had answers of "yes" and "no." The first item was adapted from Vahratian, Patel, Wolff, and $\mathrm{Xu}$ (2008), and we created the second item to assess men's intentions to support EC use.

Demographic Characteristics. Demographic characteristics included age, ethnicity, major (or desired major), grade point average (GPA), parents' highest level of completed education, religious affiliation, and class standing (freshman, sophomore, or higher).

\section{Analyses}

All surveys were entered and analyzed using SPSS version 20.0 (IBM Inc., 2011). 
Descriptive Statistics. Descriptive statistics were stratified by gender and included all demographic variables, independent variables, and dependent variables. Chi-square tests and ttests were calculated to determine whether there were any gender differences on any of these variables.

Inferential Statistics. Inferential statistics were calculated to assess the relationship between each of the independent variables and the dependent variable, for each gender separately. Specifically, bivariate logistic regression models were run to assess the extent to which each knowledge item, each perception item, past experiences with pregnancy, contraception use, and all demographic variables, were related to intentions to use EC for females and support of EC for males. We chose the strategy of analyzing individual items rather than entire scales because in preliminary analyses, entire scale scores were not associated with the study outcomes. Last, two multivariate logistic regression models were performed, one for each gender separately, to determine which of the predictors and demographic variables that were significant in the bivariate analyses remained significant in multivariate analyses.

\section{Results}

Results are presented for females first, followed by males.

\section{Females}

Table 1 displays descriptive statistics of the sample. Among the 96 females, most were White (55.4\%) and freshmen (37.9\%). Average age was 22.35 ( $\mathrm{SD}=7.23)$. Nearly three-fourths of the females (73.4\%) claimed they had penilevaginal intercourse in their lifetime, and of those, $40.0 \%$ had used EC. Of those who reported using EC, the most common reason for doing so was "no birth control" (34.2\%) and "condom slipped or broke off" (26.3\%). Approximately one in eight participants reported unplanned pregnancies (12.8\%), and nearly one in ten $(9.5 \%)$ had at least one abortion. Compared to the male sample in this study, the female sample was significantly older $(p<.01)$, had a higher percentage of freshmen and a lower percentage of sophomores $(p<.01)$, and lower rates of EC use (versus males' partners using EC) $(p<.05)$. See Table 1 for further details.

Table 2 displays bivariate and multivariate logistic regression results for EC use intentions. This table only includes those predictor variables that were significantly associated with at least one outcome (EC use intentions for females or support for partner's EC use among men) in bivariate analyses. Among females, knowing that EC can be purchased without a prescription in California, $(p<0.01)$, the belief that EC is worth using even if the monetary cost is high $(p<.001)$, and past EC use $(p<0.05)$ were associated with higher rates of intention to use EC. Conversely, the belief that EC is morally wrong $(p<.0001)$ and having had an abortion previously $(p<0.05)$ were associated with lower rates of intentions to use EC. These associations remained significant in the multivariate model, with the exception of past EC use, which was not included to improve model fit. Nagelkerke $\mathrm{R}^{2}$ for this model was .50, which indicates very strong model fit, specifically that the model explained half of the variation in EC use intentions in the sample.

\section{Males}

Table 1 displays descriptive statistics of the sample for males. Of the 118 participants, the most frequent demographic characteristics were White $(57.7 \%)$ and being a sophomore (46.4\%). Nearly one in 11 participants reported unplanned pregnancies (8.7\%), and over one in 10 participants (10.3\%) had experienced at least one abortion with a current or past sexual partner. Average age was 20.25 years $(\mathrm{SD}=$ 2.40). Over four fifths of the participants $(81.6 \%)$ reported having penile-vaginal intercourse in their lifetime and among them, $58.3 \%$ had at least one sexual partner use EC. When asked about the reason for EC, participants reported "no birth control (31.9\%)" and "condom slipped or broke off (31.9\%)."

Table 2 displays bivariate and multivariate logistic regression results. For men's bivariate results, the perception that using EC is morally wrong $(p<.001)$ and that EC encourages 
promiscuity $(p<.01)$ were negatively associated with EC use intentions. Conversely, the perception that EC is worth using even if the monetary cost is high $(p<0.01)$ was positively associated with EC use intentions. All of these variables were included in the subsequent multivariate linear regression model.

For the multivariate linear regression model, none of the individual predictor variables were significantly related to men's intentions to support their partner's EC use. The predictor that was closest to being statistically significant was EC use is morally wrong $(p=.056)$. Nevertheless, Nagelkerke $\mathrm{R}^{2}$ for this model was .486, which indicates very strong model fit, meaning that the model explained nearly half of the variation in EC support intentions in the sample. The lack of statistical significance for the individual predictors in this model is likely due to their high correlations with each other, even though multicollinearity was not an issue.

\section{Table 1.}

Demographic Characteristics of the Sample

\begin{tabular}{|c|c|c|c|}
\hline & Females $(n=96)$ & Males $(n=118)$ & $\chi^{2}$ or $t$ \\
\hline Physical Education or Health major & $38.9 \%$ & $30.4 \%$ & 1.62 \\
\hline Religious background & & & 3.98 \\
\hline Catholic & $30.9 \%$ & $29.2 \%$ & \\
\hline Non-Catholic Christian & $27.7 \%$ & $35.4 \%$ & \\
\hline Other & $19.1 \%$ & $14.3 \%$ & \\
\hline None & $22.3 \%$ & $21.2 \%$ & \\
\hline Father was a college graduate & $35.5 \%$ & $40.3 \%$ & 1.01 \\
\hline Mother was a college graduate & $37.4 \%$ & $33.0 \%$ & 2.35 \\
\hline Year in college & & & $13.31 * *$ \\
\hline Freshman & $37.9 \%$ & $26.8 \%$ & \\
\hline Sophomore & $35.8 \%$ & $46.4 \%$ & \\
\hline Junior or Senior & $20.0 \%$ & $26.7 \%$ & \\
\hline Race/Ethnicity & & & 6.39 \\
\hline White & $55.4 \%$ & $57.7 \%$ & \\
\hline Asian & $20.5 \%$ & $23.4 \%$ & \\
\hline Hispanic & $22.9 \%$ & $13.5 \%$ & \\
\hline Other & $1.2 \%$ & $5.4 \%$ & \\
\hline Sexually Active & $73.4 \%$ & $81.6 \%$ & 1.55 \\
\hline Ever taken EC/ partner had taken EC & $40.0 \%$ & $58.3 \%$ & $4.62 *$ \\
\hline Experienced an unplanned pregnancy & $12.8 \%$ & $8.7 \%$ & .18 \\
\hline Experienced an abortion & $9.5 \%$ & $10.3 \%$ & 1.83 \\
\hline High school GPA & $3.19(\mathrm{SD}=0.60)$ & $3.09(\mathrm{SD}=0.43)$ & 1.17 \\
\hline Age & $22.35(\mathrm{SD}=7.23)$ & $20.25(\mathrm{SD}=2.40)$ & $2.70^{* *}$ \\
\hline
\end{tabular}


Table 2.

Logistic Regression Results for Intentions to Use EC for Females and Intentions to Support EC Use for Males

\begin{tabular}{lrrrr}
\hline & \multicolumn{2}{c}{ Females } & \multicolumn{2}{c}{ Males } \\
\hline Knowledge & OR & AOR & OR & AOR $^{2}$ \\
& $95 \%$ CI & $95 \%$ CI & $95 \%$ CI & $95 \%$ CI \\
\hline I can obtain EC at any pharmacy in & $4.21^{* *}$ & $4.62^{*}$ & 1.36 & -- \\
California without a prescription & $1.41-12.56$ & $1.15-18.52$ & $0.15-12.18$ & \\
$\begin{array}{l}\text { Perception } \\
\text { I feel emergency contraception is }\end{array}$ & & & & \\
morally wrong & $0.46^{* * *}$ & $0.40^{* *}$ & $0.26^{* * *}$ & 0.44 \\
EC encourages promiscuity & $0.30-0.70$ & $0.22-0.73$ & $0.12-0.57$ & $0.19-1.02$ \\
& 0.87 & -- & $0.17^{* *}$ & 0.33 \\
$\begin{array}{l}\text { EC is worth using even if the } \\
\text { monetary cost is high }\end{array}$ & $2.50^{* * *}$ & $2.35^{*}$ & $0.05-0.53$ & $0.09-1.21$ \\
Past Experiences with pregnancy & $1.49-4.19$ & $1.19-4.65$ & $1.33-4.40$ & $0.81-4.31$ \\
$\begin{array}{l}\text { Experienced (or partner has } \\
\text { experienced) at least } 1 \text { abortion }\end{array}$ & & & & - \\
Have used (or partner has used) EC in & $0.09-0.92$ & $0.01-0.99$ & & - \\
the past & $11.78^{*}$ & -- & 3 & \\
\hline
\end{tabular}

Note. Adjusted odds ratios (AORs) were adjusted for other predictor variables that were

significantly associated with EC-related outcomes in bivariate analyses.

${ }^{1}$ Past EC use was not included in the multivariate model to increase model fit. Nagelkerke $\mathrm{R}^{2}=$ .507 .

${ }^{2}$ Nagelkerke $\mathrm{R}^{2}=.486$.

${ }^{3}$ Model could not be estimated due to high error terms.

\section{Discussion}

This study examined whether knowledge and perceptions of EC were associated with intentions to use EC among college undergraduate women, as well as men's support of their partner's EC use. The demographics for both females and males were comparable to each other for major, race/ethnicity, and sexual activity status.

Knowing that EC can be obtained at any pharmacy in California without a prescription was a significant predictor of women's EC use intentions, but not men's intentions to support their female partner using EC if needed. This finding suggests that most likely, women are primarily responsible for obtaining EC if needed. Hence, raising women's awareness that EC is available over the counter without a prescription may be an effective strategy to increase EC use in circumstances where they are at high risk of becoming pregnant. Additionally, more advertisements about the availability of EC on college campuses that do provide EC might be helpful.

Among the women sampled in this study, the perception that EC use is morally wrong was related to lower rates of intentions to use EC if needed. Similarly in another study (Campbell, Busby \& Steyer, 2008), 38\% percent of respondents stated that they would use EC only if they knew it worked before fertilization or implantation. Furthermore, in our study we found the belief that EC is worth using even if the monetary cost is high was associated with EC use intentions. It is possible that endorsement of this belief is a proxy for being knowledgeable of how EC works (e.g., that it 
prevents rather than terminates a pregnancy), and that EC is effective if used in the intended manner (e.g., within 72 hours of last sexual intercourse). Thus, the findings of our study, combined with findings of previous research, indicate that women's willingness to use EC might increase if they were better educated about how EC works, where it can be purchased, and its effectiveness.

We also found that past abortions were associated with lower rates of EC use intentions. It is possible that women with an abortion history lack knowledge regarding how EC works, hence their lack of intention to use EC if needed. In one study of women ages 18-35, ambivalence regarding contraception use was linked to lower rates of contraception use (hence, higher risk for pregnancy and subsequent abortion) (Neustadt, Holmquist, Davis, \& Gilliam, 2011). In other studies outside of the U.S., the majority of women who received post-abortion counseling were either unaware of modern contraceptive methods or were not using them at the time of their pregnancy (Ceylan, Ertem, Saka, \& Akdeniz, 2009; Mayi-Tsonga, Obiang, Minkobame, Ngouafo, Ambounda, \& DeSousa, 2014). However, following counseling, the majority of them accepted and used contraception at follow-up. These findings suggest that post-abortion counseling is strongly needed among women who have experienced an abortion to increase their intentions to use contraceptives, including EC if needed.

Our results for males suggested that moral objections to EC use were most predictive of their intentions to support their sexual partners in using EC. Previous research has indicated that although college-aged, single men generally express a strong desire to prevent pregnancy, there are several other dynamic factors (e.g., religious upbringing, socioeconomic circumstances, degree of family connectedness, and quality of peer relationships) that dictate whether or not men will actually support contraceptive use (Raine, Gard, Boyer, Haider, Brown, Hernandez \& Harper, 2010). Hence, sexual health intervention specialists may consider encouraging college students to have discussions about contraception options with their potential sexual partners. Such discussions may help men and women choose sexual partners who have more compatible moral beliefs regarding EC use.

Although we did not seek to estimate rates of EC use among college students, it is worth noting that self-reported rates of EC use was relatively high among our sample compared to other samples in previous studies. Specifically, 40\% of the sexually active females in our sample reported lifetime EC use, compared to only 23\% in a nationwide sample of sexually active women ages 20-24 in 2006-2010. The high rate of self-reported EC use in our study could be attributed to increasing availability and popularity of EC during the study period (20092010), as well as the study setting (a large public college in southern California, as opposed to a smaller, religious-based college), and the classes surveyed (personal health classes, which may indicate an increased interest in health-related topics compared to the average college student). The relatively high rate of EC use reported by males in this study (regarding their female partners' use of EC) is difficult to interpret, because it is not clear whether male partners are reliable reporters of their partners' EC use.

\section{Limitations}

Some limitations of the present study need to be considered. First, the design of this study did not allow us to determine whether our predictor variables preceded EC use intentions among women and support for EC use among men. Second, this study was limited by the selfreporting accuracy of the participants, which may be subject to recall bias, a lack of knowledge (e.g., males' knowledge of their female partners' EC use), and answering questions in a socially desirable manner. Third, the relatively small sample sizes utilized in this study resulted in relatively large confidence intervals for the odds ratios derived from our analyses. Larger sample sizes would have provided more reliable estimates of the relationships between the predictors and ECrelated outcomes in this study. Fourth, this study included individuals who were primarily between the ages of 18 and 23 and were enrolled in an introductory general education course in a 
community college in southern California. Hence, the results may not be generalizable to non-college-aged individuals, those not attending college, students who live in a more traditional university setting (e.g., not a commuter campus), those who attend religiousaffiliated universities, and those who reside in regions other than southern California.

\section{Conclusion}

Our findings suggest that males' moral stance regarding EC use is predictive of their intentions to support their sexual partners in their use of EC. This finding is highly relevant to future unintended pregnancy prevention efforts, since male partners' support for EC use has been related to women's actual use of EC (Pratt, Stephenson, \& Mann, 2014). Hence, male partners appear to play a significant role in contraceptive decisions. Furthermore, intervention strategies utilizing media and friendship networks to promote EC use are needed. Such approaches are likely to be effective, as studies have determined that adolescents get most of their contraceptive information from friends and coital partners
(Ryan, Franzetta, Manlove \& Holcombe, 2007; Whitley, 1990).

Encouraging male involvement in all contraceptive decisions and expanding accessibility to EC may help young men and women prevent unintended pregnancies. For example, social support interventions that involve male partners are already being implemented to successfully increase women's rates of breast self-examinations and mammograms (Kagawa-Singer, Tanjasiri, Valdez, Yu \& Foo, 2009). Involvement of males in contraception efforts, including EC use, appear to be promising, because the evidence provided in this study and other studies (e.g,, Neustadt, Holmquist, Davis, \& Gilliam, 2011; Pratt, Stephenson, \& Mann, 2014) suggest that a men and women think differently about contraception and a woman's relationship with her male partner may play a role in contraceptive decisions.

\section{Acknowledgements}

We would like to thank Anna Hanlon, California State University, Fullerton and Orange Coast College for their support. We also thank Dr. Laura Chandler for her guidance.

\section{References}

American College Health Association-National College Health Assessment II (ACHA-NCHAII) (2013). Spring 2013 reference group executive summary. Retrieved from: http://www.achancha.org/docs/ACHA-NCHA-II_ReferenceGroup_ExecutiveSummary_Spring2013.pdf

Brindis, C., Barenbaum, M., Sanchez-Flores, H., McCarter, V. \& Chand, R. (2005). Let's hear it for the guys: California's male involvement program. International Journal of Men's Health, 4(1), 2953. Retrieved from: http://mensstudies.metapress.com/content/nu8jjt416q405u68/

Campbell, J., Busby, S. \& Steyer, T. (2008). Attitudes and beliefs about emergency contraception among patients at academic family medicine clinics. Annals of Family Medicine, 6, S23-S27. Retrieved from: http://www.ncbi.nlm.nih.gov/pubmed/18195304

Centers for Disease Control and Prevention (CDC) (2014). Unintended pregnancy prevention. Retrieved from: http://www.cdc.gov/reproductivehealth/UnintendedPregnancy/index.htm

Centers for Disease Control and Prevention (CDC) (2010). Morbidity and Mortality Weekly Report $(M M W R)$. U.S. Medical Eligibility Criteria for Contraceptive Use, 2010. Retrieved from: http://www.cdc.gov/mmwr/preview/mmwrhtml/rr5904a1.htm?s_cid=rr5904a1_e\#tab1

Ceylan, A., Ertem, M., Saka, G., \& Akdeniz, N. (2009). Post abortion family planning counseling as a tool to increase contraceptive use. BMC Public Health, 9, 20. Retrieved from: www.biomedcentral.com/1471-2458/9/20

Daniels, K., Jones, J. \& Abma, J., (2013). Use of emergency contraception among women aged 15-44: United States, 2006-2010. NCHS data brief, no 112. Hyattsville, MD: National Center for Health Statistics. 2013. Retrieved from: http://www.cdc.gov/nchs/data/databriefs/db112.pdf 
Fitzpatrick, V., Mouttapa, M., Tanjasiri, S.P., Napoli, J./ Californian Journal of Health Promotion 2014, Volume 12, Issue 2, 78-89.

De La Rochebrochard, E. \& Joshi, H. (2013). Children born after unplanned pregnancies and cognitive development at 3 years: Social differentials in the United Kingdom Millennium Cohort. American Journal of Epidemiology, 178(6), 910-920. Retrieved from: http://www.ncbi.nlm.nih.gov/pmc/articles/PMC3775543/

Ellerston, C. (1996). History and efficacy of emergency contraception: Beyond Coca-Cola. Family Planning Perspectives, 28(2), 44-48. Retrieved from: https://guttmacher.org/pubs/journals/2804496.html

Finer, L. \& Zolna, M., (2011). Unintended pregnancy in the United States: Incidence and disparities, 2006. Contraception, 84(5): 478-485. Retrieved from: http://www.ncbi.nlm.nih.gov/pmc/articles/PMC3338192/

Finer, L. \& Zolna, M., (2014). Shifts in intended and unintended pregnancies in the United States, 20012008. American Journal of Public Health, 104, S43-S48. Retrieved from: http://www.ncbi.nlm.nih.gov/pubmed/24354819

Food and Drug Administration (2013). FDA approves Plan B One-Step emergency contraceptive for use without a prescription for all women of childbearing potential. (2013, June 20). Retrieved from: http://www.fda.gov/newsevents/newsroom/pressannouncements/ucm358082.htm

Foster, D., Ralph, L., Arons, A., Brindis, C. \& Harper, C. (2006). Trends in knowledge of emergency contraception among women in California, 1999-2004. Women’s Health Issues, 17(1), 22-28. Retrieved from: http://www.ncbi.nlm.nih.gov/pubmed/17321944

Hickey, M. (2009). Female college students' knowledge, perceptions and use of emergency contraception. Journal of Gynecologist and Neonatal Nurses, 38(4), 399-405. Retrieved from: http://www.ncbi.nlm.nih.gov/pubmed/19614875

Hummer, R. A., Hack, K. A. \& Raley, R. K. (2004). Retrospective reports of pregnancy wantedness and child well-being in the United States. Journal of Family Issues, 25(3), 404-428. Retrieved from: http://jfi.sagepub.com/content/25/3/404.short

IBM Corp. Released 2011. IBM SPSS Statistics for Windows, Version 20.0. Armonk, NY: IBM Corp.

Iuliano, A., Speizer, I., Santelli, J. \& Kendall, C. (2006). Reasons for contraceptive nonuse at first sex and unintended pregnancy. American Journal of Health Behavior 30(1), 92-102. Retrieved from: http://www.ncbi.nlm.nih.gov/pubmed/16430324

Kagawa-Singer, M., Tanjasiri, S. P., Valdez, A., Yu, H. \& Foo, M. A. (2009). Outcomes of a breast health project for Hmong women and men in California. American Journal of Public Health, 99, S467-S473. Retrieved from: http://www.ncbi.nlm.nih.gov/pubmed/19443830

Kelley, K. (1998). Affective responses toward contraceptive topics and behavior scale. Handbook of Sexuality-Related Measures, 162. Retrieved from:

http://books.google.com/books?hl=en\&lr=\&id=EFPs55zAKcC\&oi=fnd\&pg=PA162\&dq=Affect ive+responses+toward+contraceptive+topics+and+behavior+scale.\&ots=QA7qKq6M8A\&sig=El N4oxbruToDF3nIVrztN3Rmumk\#v=onepage\&q=Affective\%20responsre\%20toward\%20contrac eptive\%20topics\%20and\%20behavior\%20scale.\&f=false

Miller, L. (2011). College student knowledge and attitudes toward emergency contraception. Contraception, 83(1), 68-73. Retrieved from: http://www.ncbi.nlm.nih.gov/pubmed/21134506

Mayi-Tsonga, S., Obiang, P.A., Minkobame, U., Ngouafo, D., Ambounda, N., \& DeSousa, M.H. (2014). Introduction of post-abortion contraception, prioritizing long-lasting reversible contraceptives, in the principal maternity hospital in Gabon. International Journal of Gyneacology \& Obstetrics, 126(Suppl1), S45-S48. Retrieved from: www.ncbi.nlm.nih.gov/pubmed/24745694

Moreau, C., Bouver, J., Goulard, H. \& Bajos,N. (2005). The remaining barriers to the use of emergency contraception: Perception of pregnancy risk by women undergoing induced abortions. Contraception, 71, 202-207. Retrieved from: http://www.ncbi.nlm.nih.gov/pubmed/15722071

Neustadt, A., Holmquist, S., Davis, S. \& Gilliam, M. (2011) Sexual, relationship, contraceptive, and personal factors influencing emergency contraception use: A qualitative study. Contraception, 84(3), 266-272. Retrieved from: http://www.ncbi.nlm.nih.gov/pubmed/21843692 
Nguyen, B. \& Zaller, N. (2009) Male Access to over-the-counter emergency contraception a survey of acceptability and barriers in Providence, Rhode Island. Women’s Health Journal, 19(6), 365-372. Retrieved from: http://www.ncbi.nlm.nih.gov/pubmed/19879451

Pratt, R., Stephenson, J., \& Mann, S. (2014). What influences contraceptive behaviour in women who experience unintended pregnancy? A systematic review of qualitative research. Journal of Obstetrics and Gynaecology, 9, 1-7. Retrieved from: http://informahealthcare.com/doi/abs/10.3109/01443615.2014.920783

Raine, T., Gard, J., Boyer, C., Haider, C., Brown, B., Hernandez, F. \& Harper, C. (2010). Contraceptive decision-making in sexual relationships: Young men's experiences, attitudes and values. Culture, Health \& Sexuality, 12(4), 373-386. Retrieved from: http://www.ncbi.nlm.nih.gov/pmc/articles/PMC2854868/

Ryan, S., Franzetta, K., Manlove, J. \& Holcombe, E. (2007). Adolescents’ discussions about contraception or STDs with partners before first sex. Perspectives on Sexual and Reproductive Health, 39(3), 149-157. Retrieved from: http://www.ncbi.nlm.nih.gov/pubmed/17845526

Shoveller, J., Chabot, C., Soon, J. \& Levine, M. (2007). Identifying barriers to emergency contraception use among young women from various sociocultural groups in British Columbia, Canada. Perspectives on Sexual and Reproductive Health, 39(1), 502-515. Retrieved from: http://www.ncbi.nlm.nih.gov/pubmed/17355377

Tanjasiri, S. P., Mouttapa, M., Sablan-Santos, L., \& Quitugua, L. F. (2012). Exploring Factors Promoting Cervical Cancer Screening among Chamorro Women in California. Journal of Cancer Education, 27(4), 725-730.

Trieu, S., Shenoy, D., Bratton, S. \& Marshak, H. (2011) Provisions of emergency contraception at student health centers in California Community Colleges. Women's Health Issues, 21(6), 431-437. Retrieved from: http://www.ncbi.nlm.nih.gov/pubmed/21703870

Trussel, J., Ellertson, C. \& Stewart (1996). The Effectiveness of the Yuzpe Regimen of Emergency Contraception. Family Planning Perspectives, 28(2), 58-67. Retrieved from: http://www.popline.org/node/296534

Trussell, J. (2007). The cost of unintended pregnancy in the United States. Contraception, 75(3):168-70. Retrieved from: $\quad$ http://www.ncbi.nlm.nih.gov/pubmed/17303484

U.S. Department of Health and Human Services (HHS) (2014). Office of Disease Prevention and Health Promotion. Healthy People 2020. Washington, DC. Retrieved from: http://healthypeople.gov/2020/topicsobjectives2020/objectiveslist.aspx?topicId=13

Udry, J. R. (2003). The National Longitudinal Study of Adolescent Health (Add Health), Wave III, 20012002. Retrieved from: http://www.disc.wisc.edu/Codebooks/qg-067-002.pdf

Vahratian, A., Patel, D. A., Wolff, K., \& Xu, X. (2008). College Students’ Perceptions of Emergency Contraception Provision. Journal of Women's Health, 17(1), 103-111. Retrieved from: http://www.ncbi.nlm.nih.gov/pmc/articles/PMC2635885/

Whitley, B. (1990). College student contraceptive use: A multivariate analysis. The Journal of Sex Research, 27(2), 305-313. Retrieved from: http://www.popline.org/node/377213

Whittaker, P., Berger, M., Armstrong, K. Felice, T.L., \& Adams, J. (2007) Characteristics associated with emergency contraception use by family planning patients: A prospective cohort study. Perspectives on Sexual and Reproductive Health, 39(3), 158-166. Retrieved from: http://www.ncbi.nlm.nih.gov/pubmed/17845527

Wu, J., Meldrum, S., Dozier, A., Stanwood, N. \& Fiscella, K. (2008). Contraceptive nonuse among U.S. women at risk for unplanned pregnancy. Contraception, 78(4), 284-289. Retrieved from: http://www.contraceptionjournal.org/article/S0010-7824(08)00323-5/abstract 


\author{
Author Information \\ Veronica Fitzpatrick, MPH, CHES \\ Department of Health Science \\ California State University, Fullerton \\ *Michele Mouttapa \\ California State University, Fullerton \\ Department of Health Science \\ PO Box 6870, Fullerton, CA 92834 \\ E-mail: mmouttapa@ fullerton.edu. \\ Sora Park Tanjasiri, DrPH, MPH \\ Department of Health Science \\ California State University, Fullerton \\ James Napoli, MPH(c) \\ Department of Health Science \\ California State University, Fullerton \\ * corresponding author
}

